RODRIGUES, Tonny Kerley de Alencar; OLIVEIRA, Daniel Max de; GOMES, Raniele Cimara da Conceição. A relação accountability - corrupção: Uma reflexão conceitual dos achados teóricos. Revista Eletrônica Direito e Política, Programa de Pós-Graduação Stricto Sensu em Ciência Jurídica da UNIVALI, Itajaí, v.11, n.1, $1^{0}$ quadrimestre de 2016. Disponível em: www.univali.br/direitoepolitica - ISSN 1980-7791.

\title{
A RELAÇÃO ACCOUNTABILITY - CORRUPÇÃO: UMA REFLEXÃO CONCEITUAL DOS ACHADOS TEÓRICOS
}

\author{
THE ACCOUNTABILITY RELATIONSHIP - CORRUPTION: A CONCEPT \\ REFLECTION OF FINDINGS THEORETICAL
}

Tonny Kerley de Alencar Rodrigues ${ }^{1}$

Daniel Max de Oliveira²

Raniele Cimara da Conceição Gomes ${ }^{3}$

SUMÁRIO: Introdução; 1.Corrupção; 2. Esforços de combate à corrupção no Brasil; 3. Esforços de combate à corrupção no Brasil; 4. Accountability: aspectos conceituais; Principais achados teóricos; A relação Accountability - corrupção sob a ótica dos construtos teóricos; Considerações finais; Referências

\section{RESUMO}

Casos de corrupção tem se tornado um retrato do cotidiano da atuação dos agentes públicos brasileiros. Diante disso, diversas técnicas têm sido empregadas no intuito de erradicar ou mesmo minimizar os efeitos da corrupção, dentre elas destaca-se a accountability. Assim, este artigo tem por objetivo descrever como os mecanismos de accountability têm sido analisados por estudiosos de administração pública diante do problema eminente que representa a corrupção na sociedade brasileira e especificamente na classe política utilizando como foco de análise os principais construtos teóricos que tratam das temáticas, accountability e corrupção. Para isso reportou-se a uma abordagem qualitativa de natureza descritiva e para a interpretação dos dados foi utilizada a técnica de análise tipológica. Os resultados apontam uma notória descrença dos teóricos para com os mecanismos de accountability, pois sempre os concebem atribuindo-Ihes características como fragilidade e ineficácia.

\footnotetext{
1 Doutorando em Administração Coppead Graduate Business School/UFRJ, Mestre em Administração pela Universidade Federal de Lavras, professor da Faculdade Santo Agostinho FSA, Teresina, Piauí, Brasil, Coordenador Geral do Centro de Pesquisas FSA JUNIOR e editor da Revista FSA, tonny.rodrigues@coppead.ufrj.br.

2 Mestrando em Administração pela Universidade Federal de Santa Catarina, Graduado em Administração pela Faculdade Santo Agostinho, Teresina, Piauí, Brasil, danielmax2011@gmail.com.

3 Graduanda em Psicologia pela Faculdade Santo Agostinho, Teresina, Piauí, Brasil, bolsista PIBIC/FSA, ranny_cimara@hotmail.com.
} 
RODRIGUES, Tonny Kerley de Alencar; OLIVEIRA, Daniel Max de; GOMES, Raniele Cimara da Conceição. A relação accountability - corrupção: Uma reflexão conceitual dos achados teóricos. Revista Eletrônica Direito e Política, Programa de Pós-Graduação Stricto Sensu em Ciência Jurídica da UNIVALI, Itajaí, v.11, n.1, 10 quadrimestre de 2016. Disponível em: www.univali.br/direitoepolitica - ISSN 1980-7791.

PALAVRAS-CHAVE: accountability; corrupção; eficácia.

\section{ABSTRACT}

Corruption cases has become a picture of the everyday activities of Brazilian public officials. Thus, various techniques have been employed in order to eradicate or minimize the effects of corruption, among them there is the accountability. Thus, this article aims to describe how the accountability mechanisms have been analyzed by public administration scholars before the eminent problem is corruption in Brazilian society and specifically in the political class using as focus of analysis the main theoretical constructs dealing with issues, accountability and corruption. For this reported to a qualitative approach of a descriptive nature and interpretation of the data was used the typological analysis technique. The results show a marked distrust of theoretical towards accountability mechanisms, as always conceive giving them characteristics as weakness and inefficiency

KEYWORDS: accountability; corruption; efficiency.

\section{INTRODUÇÃO}

A corrupção e o descaso com a coisa pública são uma marca negativa da sociedade brasileira. Casos de corrupção são tão frequentes que já se tornaram banais aos olhos dos cidadãos. A corrupção, em seu sentido literário, refere-se à intenção voluntária que culmina na apropriação (in)direta, desvios de recursos públicos ou fraude organizada e reiterada de atividades estatais de autorização, concessão ou fiscalização relativas a interesses, bens e atividades econômicas, por parte de agentes públicos e privados, mas com a necessária participação dos primeiros $^{4}$.

Diante do problema exposto, diversas técnicas têm sido empregadas no intuito de erradicar ou mesmo minimizar os efeitos da corrupção, dentre elas destaca-se a accountability. O termo accountability, geralmente associado à terminologia "responsabilização", representa um dos principais mecanismos de garantia de transparência e eficácia dos serviços públicos, além de mediar, de forma democrática, a relação entre representantes e representados. A accountability

\footnotetext{
${ }^{4}$ MELO, C. A. V. Alta Corrupção Como Resposta a Baixos Níveis de Accountability.2003, 185 f. Dissertação (Mestrado em Ciências Políticas) - Centro de Filosofia e Ciências Humanas, Universidade Federal de Pernambuco, Recife, 2003.
} 
RODRIGUES, Tonny Kerley de Alencar; OLIVEIRA, Daniel Max de; GOMES, Raniele Cimara da Conceição. A relação accountability - corrupção: Uma reflexão conceitual dos achados teóricos. Revista Eletrônica Direito e Política, Programa de Pós-Graduação Stricto Sensu em Ciência Jurídica da UNIVALI, Itajaí, v.11, n.1, $1^{0}$ quadrimestre de 2016. Disponível em: www.univali.br/direitoepolitica - ISSN 1980-7791.

impõe aos agentes públicos que estes prestem contas à população diante de suas ações ${ }^{5}$.

No entanto, diante dos inúmeros casos de corrupção envolvendo agentes públicos que diariamente preenchem as páginas dos jornais e denigre a imagem da classe política brasileira, os mecanismos de accountability têm sido questionados e a definição que na teoria demonstra ser perfeita na prática apresenta irregularidades notáveis. Diante dessa problemática, entende-se que seria interessante analisar como a accountability, na figura de seus mecanismos, tem sido vista pela ótica de especialistas em gestão pública e como sua atuação diante da corrupção é percebida pelos mesmos.

Assim, este artigo tem por objetivo investigar como os mecanismos de accountability têm sido analisados por estudiosos de administração pública diante do problema eminente que representa a corrupção na sociedade brasileira e, especificamente, na classe política. Para isso reportou-se aos principais construtos teóricos que tratavam das duas temáticas, accountability e corrupção, de modo a evidenciar os principais argumentos e concepções dos autores diante do fenômeno estudado.

Metodologicamente, a pesquisa pode ser concebida como qualitativa de natureza descritiva e para a interpretação dos dados foi utilizada a técnica de análise tipológica Bellotto ${ }^{6}$. A análise tipológica é um procedimento descritivo que objetiva extrair de um material mais extenso elementos típicos e descrevê-los com um maior grau de detalhe. A ideia fundamental defendida por este método é que técnicas descritivas podem revelar maiores detalhes em materiais sinópticos.

Para atender a critérios estruturais, o seguinte artigo encontra-se dividido em mais quatro seções além desta introdutória, a mencionar, o referencial teórico em que serão abordadas temáticas como corrupção, mecanismos de controle

${ }^{5}$ PINHO, J. A. G.; SACRAMENTO, A. R. S. Accountability: Já Podemos Traduzi-la Para o Português. Revista de Administração Pública, Rio de Janeiro, v. 46, n. 3, p. 1343-1368, nov./dez. 2009.

6 BELLOTTO, H. L. Arquivos Permanentes: Tratamento Documental. Rio de Janeiro: Editora FGV, 2004. 
RODRIGUES, Tonny Kerley de Alencar; OLIVEIRA, Daniel Max de; GOMES, Raniele Cimara da Conceição. A relação accountability - corrupção: Uma reflexão conceitual dos achados teóricos. Revista Eletrônica Direito e Política, Programa de Pós-Graduação Stricto Sensu em Ciência Jurídica da UNIVALI, Itajaí, v.11, n.1, 10 quadrimestre de 2016. Disponível em: www.univali.br/direitoepolitica - ISSN 1980-7791.

social e accountability. Em seguida, apresentam-se os procedimentos metodológicos, posteriormente, foram destacados os principais achados teóricos e, por fim, são descritas as considerações finais, onde são destacadas contribuições teóricas, limitações e sugestões para estudos dentro da mesma linha de pesquisa.

\section{CORRUPÇÃO}

O termo corrupção está associado a uma diversidade de práticas. Trapaça, roubo, ganho ilícito, desfalque, falsificação, fraude, suborno, peculato e nepotismo são apenas alguns deles. Este fenômeno pode ser observado numa gradação infinita que vai desde pequenos desvios de comportamento até práticas ilegais de crime organizado de várias instâncias em âmbito governamental. Cabe ainda salientar que em uma sociedade de tamanha complexidade pode-se considerar que um ato seja tomado como corrupto em uma perspectiva e perfeitamente aceitável em outra? .

Segundo $\mathrm{Brei}^{8}$, a dificuldade de se obter um consenso quanto à definição de corrupção reside no fato da existência de uma teia de complexidade teórica e prática que permeia esse fenômeno. Para o autor, a corrupção pode ser conceituada com foco no mercado, nos interesses públicos, na lei e na opinião pública. Cada foco conduz esse fenômeno a ambientes diversos de conceituação.

Neste artigo, adota-se como a definição mais adequada àquela defendida por Bezerra", onde a corrupção pode ser entendida como "o uso da autoridade ou poder no intuito de obter vantagens através da utilização do dinheiro público para beneficio próprio ou de terceiros com objetivo fraudulento". Embora a corrupção, em sua essência, fosse um privilégio de países não democráticos e de terceiro mundo observa-se que este mal encontra-se arraigado nos sistemas públicos da grande maioria das nações do mundo.

7 BREI, Z. A. A. Corrupção: Causas, Consequências e Soluções Para o Problema. Revista de Administração Pública, v. 30, n. 3, p. 103-115, mai./jun. 1996a.

8 BREI, Z. A. A. Corrupção: Dificuldades Para a Definição e Consenso. Revista de Administração Pública, Rio de Janeiro, v. 30, n.1, p. 64-76, jan./fev.1996b.

9 BEZERRA, M. O. Corrupção: Um Estudo Sobre Poder Público e Relações Pessoais no Brasil. Rio de Janeiro. Relume-Dumará. 1995. 
RODRIGUES, Tonny Kerley de Alencar; OLIVEIRA, Daniel Max de; GOMES, Raniele Cimara da Conceição. A relação accountability - corrupção: Uma reflexão conceitual dos achados teóricos. Revista Eletrônica Direito e Política, Programa de Pós-Graduação Stricto Sensu em Ciência Jurídica da UNIVALI, Itajaí, v.11, n.1, 10 quadrimestre de 2016. Disponível em: www.univali.br/direitoepolitica - ISSN 1980-7791.

De fato, a corrupção representa um ônus a qualquer sociedade, especialmente, para aquelas permeadas por grandes desigualdades sociais. Como destacam Araujo e Sanchez ${ }^{10}$, a corrupção representa "uma das mais perversas categorias criminosas", uma vez que compromete a capacidade dos governos de prover serviços públicos de qualidade à sociedade. Além disso, a corrupção compromete a consolidação e avanço de um sistema democrático.

Atos de corrupção no sistema público brasileiro são frequentes e este fato é responsável por comprometer a eficácia das três esferas do poder (executivo, legislativo e judiciário). As consequências dessas ações recaem sobre a camada mais pobre da sociedade brasileira que depende exclusivamente dos serviços públicos e são obrigadas a enfrentar a triste realidade de péssimos sistemas de educação, saúde, infra-estrutura, saneamento básico, entre outros ${ }^{11}$.

No cenário da administração pública entende-se que sempre que há um ato de corrupção existe interesse privado envolvido, ou seja, os agentes tratam a coisa pública como se privada fosse. Nessa instância os autores destacam que há duas vertentes de corrupção: a) a primeira é representada pelo ato fraudulento do funcionário público que se privilegia de sua posição para receber dinheiro para executar funções que já são de sua incumbência; b) A segunda, de maiores proporções, reside em fraudes nos processos de licitações e contratos e na fiscalização tributária de grandes empresas ${ }^{12}$.

Dados da Transparency International, organização internacional que tem por objetivo desenvolver pesquisas no intuito de mensurar o nível de corrupção de algumas nações, colocam o Brasil como um dos países com o maior índice de corrupção do mundo. As pesquisas dessa organização destacam o Brasil na posição $54^{a}$ com índice de confiança de 3,4 (onde 0 representa desconfiança

10 ARAÚJO, M..; SANCHEZ, O. A. A Corrupção e os Controles Internos do Estado. Lua Nova: Revista de Cultura e Política, São Paulo, v.65, p. 137-173, mai./ago. 2005.

11 MELO, M. P.; SILVA, M. A. Corrupção: "É Proibido Não Proibir". Reflexões Sobre a Moralidade e Improbidade na Administração Pública. Revista Jurídica, v.17, n. 33, p. 195-218, jan./jun. 2013.

12 PEREIRA, J. M. Reforma do Estado e Transparência: Estratégias de Controle da Corrupção no Brasil. In: Congresso Internacional Del CLAD Sobre la Reforma Del Estado y de la Administración Pública, 7, 2002. Anais ...CLAD, Lisboa, 2002. 
RODRIGUES, Tonny Kerley de Alencar; OLIVEIRA, Daniel Max de; GOMES, Raniele Cimara da Conceição. A relação accountability - corrupção: Uma reflexão conceitual dos achados teóricos. Revista Eletrônica Direito e Política, Programa de Pós-Graduação Stricto Sensu em Ciência Jurídica da UNIVALI, Itajaí, v.11, n.1, $1^{0}$ quadrimestre de 2016. Disponível em: www.univali.br/direitoepolitica - ISSN 1980-7791.

total e 10 confiança total), o primeiro lugar é ocupado pela Finlândia com índice de confiança $9,7^{13}$.

Diante dessa realidade torna-se evidente que a corrupção representa um dos mais graves problemas que assolam a sociedade brasileira sendo ainda responsável por outras dificuldades que tornam esse país um dos mais desiguais do mundo. Tais práticas corruptas representam, ainda, o estopim para os movimentos sociais assistidos no Brasil no último ano, o que, de certa forma, tangibiliza o descontentamento de toda uma nação com a situação vigorante ${ }^{14}$.

\section{ESFORÇOS DE COMBATE À CORRUPÇÃO NO BRASIL}

Como destacam Melo e Silva15 "a corrupção e o descaso com a coisa pública são uma marca nefasta na cultura política brasileira". No entanto, de forma contrária a esta constatação, esforços têm sido despendidos no intuito de combater e reduzir os efeitos drásticos desse problema sobre a sociedade. Leis, decretos, projetos institucionais, são alguns dos mecanismos empregados, pelo poder público, com esta finalidade ${ }^{16}$.

Desde a década de 1970 estudiosos tem se debruçado na tentativa de evidenciar soluções cabíveis a este problema e as suas consequências mais agudas. A saída para a corrupção reside no desenvolvimento de organizações políticas que

${ }^{13}$ FILgueirAS, F. A.; ARANHA, A. L. M. Controle da Corrupção e Burocracia da Linha de Frente: Regras, Discricionaridade e Reformas no Brasil. Revista de Ciências Sociais, Rio de Janeiro, v. 54, n. 2, p. 349-387, 2011.

${ }^{14}$ MORENO, A. C. Resultados das Manifestações de Junho. Disponível em: <http://g1.globo.com/brasil/linha-tempo-manifestacoes-2013/platb/category/sem -categoria/>. Acesso em: 15 mar. 2014.

15 MELO, M. P.; SILVA, M. A. Corrupção: "É Proibido Não Proibir". Reflexões Sobre a Moralidade e Improbidade na Administração Pública. Revista Jurídica, v.17, n. 33, p. 195-218, jan./jun. 2013.

${ }^{16}$ ABRUCIO, F. L. A Cooperação Federativa no Brasil: A Experiência do Período FHC e os Desafios do Governo Lula. Revista de Sociologia Política, Curitiba, n. 24, p. 41-67, jul. 2005. 
RODRIGUES, Tonny Kerley de Alencar; OLIVEIRA, Daniel Max de; GOMES, Raniele Cimara da Conceição. A relação accountability - corrupção: Uma reflexão conceitual dos achados teóricos. Revista Eletrônica Direito e Política, Programa de Pós-Graduação Stricto Sensu em Ciência Jurídica da UNIVALI, Itajaí, v.11, n.1, $1^{0}$ quadrimestre de 2016. Disponível em: www.univali.br/direitoepolitica - ISSN 1980-7791.

exercitem autoridade efetiva e dêem origem a unidades organizadas que atendam de forma concreta aos interesses públicos ${ }^{17}$.

Ao reportar-se à obra de Pereira ${ }^{18}$ e durante uma rápida pesquisa em meios eletrônicos que tratam da temática, percebe-se que algumas ações têm sido despendidas, nas últimas décadas, contra a corrupção, assim destaca-se aquelas de maior impacto: a) criação da Comissão de Ética Pública (CEP); b) a aprovação do Código de Conduta da Alta Administração Federal; c) criação da Corregedoria Geral da União; e d) criação das Comissões Parlamentares de Inquérito.

Para Pereira ${ }^{19}$ o combate à corrupção passa por medidas de fortalecimento do nível de transparência no Brasil. Nesse contexto, torna-se fundamental ter como referência a confiança que a população deposita nas instituições e nos agentes públicos. Além disso, o autor, amparado nas obras de cientistas sociais como Abramo, reafirma a complexidade de se elaborar estratégias de controle a corrupção no Brasil em detrimento de sua dimensão e peculiaridades.

Specket al. contribuíram para formar o entendimento sobre a corrupção como um fenômeno complexo, suas causas, consequências, além das providências mais adequadas para enfrentá-la ${ }^{20}$. Na ótica desse autor, o combate à corrupção perpassa por medidas como aperfeiçoamento de licitações, controle social, reforma judiciária, aumento do poder dos tribunais de contas, maior transparência e fiscalização da atuação da Receita Federal.

17 BREI, Z. A. A Corrupção: Causas, Consequências e Soluções Para o Problema. Revista de Administração Pública, v. 30, n. 3, p. 103-115, mai./jun. 1996a.

18 PEREIRA, J. M. Reforma do Estado e Transparência: Estratégias de Controle da Corrupção no Brasil. In: Congresso Internacional Del CLAD Sobre la Reforma Del Estado y de laAdministración Pública, 7, 2002. Anais... CLAD, Lisboa, 2002.

19 PEREIRA, J. M. Reforma do Estado e Controle da Corrupção da Corrupção no Brasil. Revista de Administração Mackenzie, São Paulo, v. 4, n. 1, p. 39-58, 2008.

20 SPECK, B. W. et al. Os Custos da Corrupção.CadernosAdenauer, São Paulo, n. 10, p. 9-127, 2000. 
RODRIGUES, Tonny Kerley de Alencar; OLIVEIRA, Daniel Max de; GOMES, Raniele Cimara da Conceição. A relação accountability - corrupção: Uma reflexão conceitual dos achados teóricos. Revista Eletrônica Direito e Política, Programa de Pós-Graduação Stricto Sensu em Ciência Jurídica da UNIVALI, Itajaí, v.11, n.1, 10 quadrimestre de 2016. Disponível em: www.univali.br/direitoepolitica - ISSN 1980-7791.

Ao se conceber os agentes públicos como os sujeitos dos atos de corrupção praticados no Brasil, O’Donnell ${ }^{21}$ propõe dois tipos de controle, o vertical e o horizontal. O primeiro refere-se a mecanismos que a sociedade possui para controlar o Estado, como o voto. Já o controle horizontal é aquele que somente pode ser exercido pelos poderes entre si, como aqueles exercidos por órgãos como o Ministério Público e os Tribunais de Contas.

Nos últimos anos, chamaram a atenção, nas ruas de diferentes cidades do Brasil manifestações sociais com a presença massiva da sociedade civil, com queixas variadas pleiteando desde o aumento abusivo do valor das passagens do transporte público até os péssimos sistemas de saúde e educação ${ }^{22}$. No entanto, dentre as reivindicações, era a indignação para com os atos de corrupção que dominava, e ainda domina o cenário político, naquele momento se evidenciou. Essas ações evidenciam que o combate à corrupção não está presente apenas de forma institucional, mas também em movimentos de cidadania ${ }^{23}$.

\section{ACCOUNTABILITY: ASPECTOS CONCEITUAIS}

Diversos são os estudos e pesquisas que intentam fornecer maiores evidências e explicações ao processo de accountability. No entanto, desde sua instauração no Brasil destaca-se a complexidade e a dificuldade de se adaptar o conceito, oriundo da língua inglesa, à realidade nacional. Pinho e Sacramento ${ }^{24}$ (2009) destacam que inicialmente se tentava conceber o termo tal como exposto em dicionários. Partindo dessa premissa, acrescentasse que o conceito de

21 O'DONNELL, G. Sobre o Estado, a Democratização e Alguns Problemas Conceituais. Novos Estudos Cebrap, v. 36, p. 123-145, 1993.

22 MORENO, A. C. Resultados das Manifestações de Junho. Disponível em: <http://g1.globo.com/brasil/linha-tempo-manifestacoes-2013/platb/category/sem -categoria/>. Acesso em: 15 mar. 2014.

23 MELO, M. P.; SILVA, M. A. Corrupção: "É Proibido Não Proibir". Reflexões Sobre a Moralidade e Improbidade na Administração Pública. Revista Jurídica, v.17, n. 33, p. 195-218, jan./jun. 2013.

${ }^{24}$ PINHO, J. A. G.; SACRAMENTO, A. R. S. Accountability: Já Podemos Traduzi-la Para o Português. Revista de Administração Pública, Rio de Janeiro, v. 46, n. 3, p. 1343-1368, nov./dez. 2009. 
RODRIGUES, Tonny Kerley de Alencar; OLIVEIRA, Daniel Max de; GOMES, Raniele Cimara da Conceição. A relação accountability - corrupção: Uma reflexão conceitual dos achados teóricos. Revista Eletrônica Direito e Política, Programa de Pós-Graduação Stricto Sensu em Ciência Jurídica da UNIVALI, Itajaí, v.11, n.1, 10 quadrimestre de 2016. Disponível em: www.univali.br/direitoepolitica - ISSN 1980-7791.

accountability, a priori, encontrava-se relacionado ao ato de resguardar o direito dos cidadãos, protegendo-os da má conduta burocrática ${ }^{25}$.

De modo a avançar na discussão, Gray ${ }^{26}$ afirma que o processo de accountability deve ser percebido como uma prestação de contas, ou ainda, o dever de fornecer um retorno, um acerto de contas, aqueles para quem a ação é destinada. Ao tangibilizar este conceito proposto, percebe-se que, nos pressupostos daaccountability, cabe aos agentes públicos prestar contas diante daqueles que financiam os serviços públicos, os contribuintes, a população em geral.

A definição defendida pelo autor sugere, então, que accountability envolve duas responsabilidades diferentes, no entanto, inextricavelmente relacionadas que abrangem tanto o executor quanto o beneficiário de uma determinada ação. De um lado tem-se o dever de realizar uma determinada ação, do outro, o dever de oferecer uma explicação aos atos executados.

Ao perpassar pelos conceitos de accountability, propostos pelos teóricos, percebe-se que este processo pode ser claramente traduzido em um relacionamento entre uma organização e as partes envolvidas ou relacionadas com as atividades desenvolvidas por esta instituição. Verifica-se, então, que por accountability ainda pode-se associar a ideia de responsabilização pelos atos praticados e prontidão para a prestação de contas ${ }^{27}$.

Passados as indagações quanto à adaptação e validade do conceito de accountability, alguns autores intentaram tecer comentários sobre seus benefícios à gestão, especialmente em âmbito público. Uma vez reconhecida e legitimada, a accountability representa uma ferramenta importante no fornecimento de uma

25 CAMPOS, A. M. Accountability: Quando Poderemos Traduzi-la Para o Português? Revista de Administração Pública. Rio de Janeiro, v. 4, n. 2, pp. 30-50, fev./abr.1990.

${ }^{26}$ GRAY, R. Thirty Years of Social Accounting, Reporting and Auditing: What (if anything) Have We Learnt? Business Ethics, EuropeanReview, v. 10, n.1, p.9-15, 2001.

27 MELO, M. A. "Governance e Reforma do Estado: O Paradigma Agente X Principal", Revista do Serviço Público, v. 120, n.1, Brasília, jan.-abr., 1996. 
RODRIGUES, Tonny Kerley de Alencar; OLIVEIRA, Daniel Max de; GOMES, Raniele Cimara da Conceição. A relação accountability - corrupção: Uma reflexão conceitual dos achados teóricos. Revista Eletrônica Direito e Política, Programa de Pós-Graduação Stricto Sensu em Ciência Jurídica da UNIVALI, Itajaí, v.11, n.1, $1^{0}$ quadrimestre de 2016. Disponível em: www.univali.br/direitoepolitica - ISSN 1980-7791.

governança efetiva ${ }^{28}$ e ainda representa um mecanismo de garantia de uma gestão transparente e de responsabilidade para com os beneficiários ${ }^{29}$.

Desse modo, a accountability seria uma forma de prestação de contas que permite ao cidadão o controle e a observação da conduta da organização, isto é, o conjunto de mecanismos que o permita saber se, por exemplo: o dinheiro recebido por essa organização foi bem aplicado; os recursos e bens foram geridos de forma eficaz; a organização cumpre com os seus objetivos sociais de forma ética; e além de cumprir com os seus objetivos sociais, ela atinge ganhos econômico-financeiros e possui transparência nas suas ações ${ }^{30}$.

\section{PRINCIPAIS ACHADOS TEÓRICOS}

A accountability, como já discutido anteriormente, refere-se à obrigação que agentes públicos de órgãos administrativos ou representativos têm em prestar contas de suas ações a instâncias de controle e aos próprios representados ${ }^{31}$. Em tese, o papel dos mecanismos de accountability encontra-se bem definido, ou seja, através de ações transparentes aos envolvidos e representados essa ferramenta intenta impedir práticas fraudulentas acometidas por agentes públicos, no entanto, na prática, esse discurso tem apresentado desníveis consideráveis, dado a quantidade de escândalos de corrupção presenciados no âmbito público.

${ }^{28}$ LARROUDÉ, E. R. A. Accountability de Organizações do Espaço Público não-Estatal: Uma Apreciação Crítica da Legislação Brasileira. 2006. Dissertação(Mestrado) - Fundação Getúlio Vargas, Escola de Administração de Empresas de São Paulo. São Paulo: FGV, 2006.

29 LOUREIRO, M. R.; TEIXEIRA, M. A. C.; MORAES, T. C. Democratização e Reforma do Estado: O Desenvolvimento Institucional dos Tribunais de Contas no Brasil Recente. Revista de Administração Pública, Rio de Janeiro, v. 43, n.4, pp.739-772, jul./ago. 2009.

30 CAMPOS, A. M. Accountability: Quando Poderemos Traduzi-la Para o Português? Revista de Administração Pública. Rio de Janeiro, v. 4, n. 2, pp. 30-50, fev./abr.1990.

31 O'DONNELL, G. Sobre o Estado, a Democratização e Alguns Problemas Conceituais. Novos Estudos Cebrap, v. 36, p. 123-145, 1993. 
RODRIGUES, Tonny Kerley de Alencar; OLIVEIRA, Daniel Max de; GOMES, Raniele Cimara da Conceição. A relação accountability - corrupção: Uma reflexão conceitual dos achados teóricos. Revista Eletrônica Direito e Política, Programa de Pós-Graduação Stricto Sensu em Ciência Jurídica da UNIVALI, Itajaí, v.11, n.1, 10 quadrimestre de 2016. Disponível em: www.univali.br/direitoepolitica - ISSN 1980-7791.

Dessa forma, neste estudo reportou-se à literatura que trata das duas temáticas, corrupção e accountability, no intuito de entender como os teóricos têm percebido e destacado a atuação dos mecanismos de accountability diante do problema eminente que representa a corrupção dentro da sociedade brasileira. Optou-se por essa abordagem, pois entende-se que os construtos teóricos evidenciam aspectos que uma simples análise de casos de corrupção, sem cientificidade, não poderiam revelar.

Por meio da análise de alguns dos principais construtos teóricos que tratam da temática, percebe-se que os autores demonstram uma descrença para com os mecanismos de accountability e os concebem atribuindo-Ihes características como fragilidade e ineficácia. Os mecanismos de controle, de forma muito discreta, são destacados com bons olhos, mas quando isso acontece é inevitável perceber na retórica utilizada o seu caráter quase que utópico, ou seja, os autores evidenciam seus benefícios, no entanto, são unanimes em declarar que essa é uma realidade longe de estar acessível a países como o Brasil.

\section{A RELAÇÃO ACCOUNTABILITY - CORRUPÇÃO SOB A ÓTICA DOS CONSTRUTOS TEÓRICOS}

Estudos como o de Melo ${ }^{32}$, Power e Gonzalez ${ }^{33}$, Araújo e Sanchez ${ }^{34}$, Abrucio ${ }^{35}$, Filgueiras ${ }^{36}$, Sodré e Alves ${ }^{37}$ e Pinho e Sacramento ${ }^{38}$ desmistificam o discurso de

32 MELO, C. A. V. Alta Corrupção Como Resposta a Baixos Níveis de Accountability.2003, 185 f. Dissertação (Mestrado em Ciências Políticas) - Centro de Filosofia e Ciências Humanas, Universidade Federal de Pernambuco, Recife, 2003.

33 POWER, T. J.; GONZÁLEZ, J.Cultura Política, Capital Social e Percepções Sobre Corrupção: Uma Investigação Quantitativa em Nível Mundial, Revista Sociologia Política, Curitiba, v. 21, p. 5169, nov. 2003.

34 ARAÚJO, M..; SANCHEZ, O. A. A Corrupção e os Controles Internos do Estado. Lua Nova: Revista de Cultura e Política, São Paulo, v.65, p. 137-173, mai./ago. 2005.

35 ABRUCIO, F. L. A Cooperação Federativa no Brasil: A Experiência do Período FHC e os Desafios do Governo Lula. Revista de Sociologia Política, Curitiba, n. 24, p. 41-67, jul. 2005.

36 FILGUeIRAS, F. A Tolerância a Corrupção no Brasil: Uma Antinomia Entre Normas Morais e Prática Social. Opinião Pública, Campinas, v. 15, n. 2, p. 386-421, nov. 2009.

37 SODRÉ, A. C. A.; ALVES, M. F. C. Relação Entre Emendas Parlamentares e Corrupção Municipal no Brasil: Estudos dos Relatórios do Programa de Fiscalização da Controladoria Geral da União. Revista de Administração Contemporânea, Curitiba, v. 14, n. 3, p. 414-433. Mai./jun. 2010. 
RODRIGUES, Tonny Kerley de Alencar; OLIVEIRA, Daniel Max de; GOMES, Raniele Cimara da Conceição. A relação accountability - corrupção: Uma reflexão conceitual dos achados teóricos. Revista Eletrônica Direito e Política, Programa de Pós-Graduação Stricto Sensu em Ciência Jurídica da UNIVALI, Itajaí, v.11, n.1, 10 quadrimestre de 2016. Disponível em: www.univali.br/direitoepolitica - ISSN 1980-7791.

que os mecanismos de accountability representam ferrenhos combatentes contra a corrupção e demonstram uma realidade bem distinta daquela que agentes públicos, defensores dessa ferramenta de controle, costumam adotar. Para esses autores, os mecanismos de accountability são frágeis e ineficazes, e essa constatação pode ser evidenciada pela enorme quantidade de casos de corrupção no sistema público brasileiro.

O estudo de Melo $^{39}$ é fundamental na compreensão da dimensão da ineficácia da accountability diante da atuação fraudulenta de agentes públicos. O autor, em seu estudo, oferece um mapeamento empírico da corrupção política no Brasil, esse mapeamento é oriundo de uma investigação das atividades governamentais mais sujeitas a atos corruptos. Através desse rebuscado estudo ele define corrupção como:

Apropriação direta e desvios de recursos públicos ou fraude organizada e reiterada de atividades estatais de autorização, concessão ou fiscalização relativas a interesses, bens e atividades econômicas, por parte de agentes públicos e privados, mas com a necessária participação dos primeiros ${ }^{40}$.

Após declarar sua posição quanto à corrupção, o autor destaca ações do sistema institucional as quais denomina de "deslocamentos" para o combate à corrupção, com destaque para os mecanismos de accountability. Utilizando de argumentos metafóricos Melo afirma que, para um arranjo institucional funcionar de modo sistêmico e equilibrado os mecanismos de defesa devem ser proporcionais aos de ataque, ou seja, os órgãos públicos devem dispor de sistemas bem organizados que possam reprimir atos corruptos.

\footnotetext{
38 PINHO, J. A. G.; SACRAMENTO, A. R. S. Corrupção e Accountability no Brasil: Um Olhar A partir de Organizações da Sociedade Civil. In: ENCONTRO DA ASSOCIAÇÃO NACIONAL DE PESQUISA E PÓS-GRADUAÇÃO EM ADMINISTRAÇÃO, 36, 2012. Anais... Rio de Janeiro: Anpad, 2012.

39 MELO, C. A. V. Alta Corrupção Como Resposta a Baixos Níveis de Accountability.2003, 185 f. Dissertação (Mestrado em Ciências Políticas) - Centro de Filosofia e Ciências Humanas, Universidade Federal de Pernambuco, Recife, 2003.

40 MELO, C. A. V. Alta Corrupção Como Resposta a Baixos Níveis de Accountability.2003, $185 \mathrm{f}$. Dissertação (Mestrado em Ciências Políticas) - Centro de Filosofia e Ciências Humanas, Universidade Federal de Pernambuco, Recife, 2003, p. 1.
} 
RODRIGUES, Tonny Kerley de Alencar; OLIVEIRA, Daniel Max de; GOMES, Raniele Cimara da Conceição. A relação accountability - corrupção: Uma reflexão conceitual dos achados teóricos. Revista Eletrônica Direito e Política, Programa de Pós-Graduação Stricto Sensu em Ciência Jurídica da UNIVALI, Itajaí, v.11, n.1, 10 quadrimestre de 2016. Disponível em: www.univali.br/direitoepolitica - ISSN 1980-7791.

No entanto, o próprio autor menciona que enquanto de um lado têm-se indivíduos que se organizam, planejam suas ações cuidadosamente por meio de técnicas estratégicas, numa menção a grupos de corrupção, do outro, os mecanismos de controle são dispersos, lentos e suas ações, em poucos casos conseguem sobrepor-se aos atos de quadrilhas de agentes fraudulentos. Dessa forma, a tão sonhada "compatibilidade" que permitiria aos mecanismos de accountability tornarem-se eficazes não existe e em decorrência disso, esquemas de corrupção resistem por anos até serem descobertos e quando isso acontece, os indivíduos envolvidos já usufruíram de recursos desviados causando danos irreversíveis à sociedade e aos cofres públicos ${ }^{41}$.

Outro estudo que destaca a ineficácia dos mecanismos de accountabilityé o de Abrucio $^{42}$. Numa investigação que buscava primordialmente entender em qual regime de governo (democráticos ou autoritários) a corrupção é mais propícia, o autor tece comentários sobre mecanismos de controle e sua atuação diante de atos corruptos e destaca que "seria uma utopia acreditar que sistemas de controle poderiam coibir, ou ao menos diminuir, práticas de corrupção em sistemas democráticos de governo"${ }^{\prime 43}$.

Na concepção desse autor, a corrupção é um problema que sempre irá existir, está intrínseco ao comportamento humano, assim que houver uma oportunidade para alguém se beneficiar de sistemas públicos para obter vantagens isso acontecerá. Mecanismos de controle representam meras formalidades, convenções que os governos criam para ludibriar a sociedade civil, para mostrar a eles que medidas estão sendo tomadas, no entanto, os agentes públicos mais do que qualquer outro cidadão tem conhecimento da dimensão do problema da corrupção, pois conhece os meandros que a cercam. Por meio das ideias expostas, talvez esse seja um dos autores mais pessimistas diante da

${ }^{41}$ POWER, T. J.; GONZÁLEZ, J.Cultura Política, Capital Social e Percepções Sobre Corrupção: Uma Investigação Quantitativa em Nível Mundial, Revista Sociologia Política, Curitiba, v. 21, p. 5169, nov. 2003.

42 ABRUCIO, F. L. A Cooperação Federativa no Brasil: A Experiência do Período FHC e os Desafios do Governo Lula. Revista de Sociologia Política, Curitiba, n. 24, jul. 2005.

${ }^{43}$ ABRUCIO, F. L. A Cooperação Federativa no Brasil: A Experiência do Período FHC e os Desafios do Governo Lula. Revista de Sociologia Política, Curitiba, n. 24, p. 41-67, jul. 2005. 
RODRIGUES, Tonny Kerley de Alencar; OLIVEIRA, Daniel Max de; GOMES, Raniele Cimara da Conceição. A relação accountability - corrupção: Uma reflexão conceitual dos achados teóricos. Revista Eletrônica Direito e Política, Programa de Pós-Graduação Stricto Sensu em Ciência Jurídica da UNIVALI, Itajaí, v.11, n.1, 10 quadrimestre de 2016. Disponível em: www.univali.br/direitoepolitica - ISSN 1980-7791.

possibilidade de combate a corrupção através de mecanismos de accontability. Ideias semelhantes a estas também podem ser encontradas no trabalho de Sodré e Alves ${ }^{44}$, com um toque a menos de rigidez.

Os autores, Sodré e Alves, por sua vez, estudam a corrupção pública verificando sua lógica e analisando que fatores podem intervir em suas manifestações. $\mathrm{Na}$ concepção desse autor a corrupção pode ser entendida como:

A interação voluntária de agentes racionais, com base em ordenamento de preferências e restrições, na tentativa de capturar, ilegalmente, recursos de organizações nas quais pelo menos um desses agentes, faz parte, sendo as ações propiciadas por ambiente de baixa accountability ${ }^{45}$.

Para Melo ${ }^{46}$, como pode ser observado acima, o termo accountability aparece no próprio conceito de corrupção e dessa forma é considerado como um dos fatores primordiais para sua ocorrência. Esse autor acrescenta à discussão a terminologia "nível" que pode ser associado ao que Meloe Power e Gonzalez ${ }^{47}$ chamam de "compatibilidade". Dessa forma o nível de accountability é responsável pelo nível de corrupção, assim, quanto menor o nível de accountability, maior será a ocorrência de episódios de corrupção no cenário da administração pública brasileira.

Sodré e Alves ${ }^{48}$ destacam a ineficácia dos mecanismos de accountability ao fazer o seguinte questionamento: como saber se o que está sendo gasto no controle da corrupção é inferior aos prejuízos causados por ela? Na concepção desse

${ }^{44}$ SODRÉ, A. C. A.; ALVES, M. F. C. Relação Entre Emendas Parlamentares e Corrupção Municipal no Brasil: Estudos dos Relatórios do Programa de Fiscalização da Controladoria Geral da União. Revista de Administração Contemporânea, Curitiba, v. 14, n. 3, p. 414-433. Mai./jun. 2010.

45 MELO, C. A. V. Alta Corrupção Como Resposta a Baixos Níveis de Accountability.2003, 185 f. Dissertação (Mestrado em Ciências Políticas) - Centro de Filosofia e Ciências Humanas, Universidade Federal de Pernambuco, Recife, 2003.

46 MELO, C. A. V. Alta Corrupção Como Resposta a Baixos Níveis de Accountability.2003, 185 f. Dissertação (Mestrado em Ciências Políticas) - Centro de Filosofia e Ciências Humanas, Universidade Federal de Pernambuco, Recife, 2003.

47 POWER, T. J.; GONZÁLEZ, J.Cultura Política, Capital Social e Percepções Sobre Corrupção: Uma Investigação Quantitativa em Nível Mundial, Revista Sociologia Política, Curitiba, v. 21, p. 5169, nov. 2003.

48 SODRÉ, A. C. A.; ALVES, M. F. C. Relação Entre Emendas Parlamentares e Corrupção Municipal no Brasil: Estudos dos Relatórios do Programa de Fiscalização da Controladoria Geral da União. Revista de Administração Contemporânea, Curitiba, v. 14, n. 3, p. 414-433. mai./jun. 2010. 
RODRIGUES, Tonny Kerley de Alencar; OLIVEIRA, Daniel Max de; GOMES, Raniele Cimara da Conceição. A relação accountability - corrupção: Uma reflexão conceitual dos achados teóricos. Revista Eletrônica Direito e Política, Programa de Pós-Graduação Stricto Sensu em Ciência Jurídica da UNIVALI, Itajaí, v.11, n.1, 10 quadrimestre de 2016. Disponível em: www.univali.br/direitoepolitica - ISSN 1980-7791.

autor, a montagem da estratégia anti-corrupção tem custado valores consideráveis para o Estado e esse investimento financeiro não se materializa em ações eficazes, ou seja, todos os recursos despendidos em ações dessa natureza de nada tem adiantado para coibir tais atos de corrupção. Destaca-se, então, que as queixas existem em decorrência da ineficácia dos mecanismos de accountability e não pelo fato de ter de empregar recursos nessas ações, já que isso representa uma obrigação do Estado.

O autor ainda destaca em seu trabalho o papel exercido pelo Tribunal de Contas da União (TCU) por representar o órgão máximo de fiscalização da Administração Pública Federal. Diferentemente do que muitos teóricos postulam sobre esse órgão, que geralmente é associado com ações eficazes de fiscalização de atos fraudulentos, o autor afirma que, na verdade, esse órgão é apenas um componente auxiliar, não possui poder de discricionariedade e depende de outras instituições, como o Ministério Público, para atuar. Esse fator evidencia a ineficácia dos mecanismos de accountability, pois o único órgão atuante no sentido de fiscalizar crimes de corrupção é relegado a ares de subordinação e tem sua atuação estagnada pela burocracia brasileira ${ }^{49}$.

Para Pinho e Sacramento ${ }^{50}$ essa profusão de escândalos de corrupção contribui para reforçar o sentimento de fragilidade dos mecanismos de accountability e isso ainda repercute no baixo interesse e envolvimento direto da sociedade civil. Os autores rebatem as concepções de alguns autores que afirmam que o Brasil possui mecanismos de accountability eficazes. Por sua vez, destacam que isto é uma inverdade, uma vez que apenas em países que apresentam altos índices de desenvolvimento e comprometimento, tanto de agentes públicos quanto da sociedade civil esta realidade poderia ser possível.

Em seu trabalho esses autores lançam o foco sobre os impactos da corrupção na sociedade civil e inversamente creditam a ineficácia dos mecanismos de

\footnotetext{
49 MELO, C. A. V. Alta Corrupção Como Resposta a Baixos Níveis de Accountability.2003, 185 f. Dissertação (Mestrado em Ciências Políticas) - Centro de Filosofia e Ciências Humanas, Universidade Federal de Pernambuco, Recife, 2003.

${ }^{50}$ PINHO, J. A. G.; SACRAMENTO, A. R. S. Accountability: Já Podemos Traduzi-la Para o Português. Revista de Administração Pública, Rio de Janeiro, v. 46, n. 3, p. 1343-1368, nov./dez. 2009.
} 
RODRIGUES, Tonny Kerley de Alencar; OLIVEIRA, Daniel Max de; GOMES, Raniele Cimara da Conceição. A relação accountability - corrupção: Uma reflexão conceitual dos achados teóricos. Revista Eletrônica Direito e Política, Programa de Pós-Graduação Stricto Sensu em Ciência Jurídica da UNIVALI, Itajaí, v.11, n.1, 10 quadrimestre de 2016. Disponível em: www.univali.br/direitoepolitica - ISSN 1980-7791.

accountability ao irrisório envolvimento da população, ou seja, percebe-se que nesse caso a fragilidade da accountability e os consequentes crimes de corrupção representam sujeito e objeto de uma relação, pois, ao mesmo tempo em que se apresentam como uma causa para a descrença populacional é uma de suas principais consequências. Cabe ainda ressaltar que tal situação é responsável por admitir que a sociedade brasileira estivesse preparada para aceitar níveis suportáveis de corrupção desde que o governante atenda as necessidades da sociedade civil num claro sentimento de passividade de uma população totalmente descrente diante de qualquer mecanismo de controle.

O trabalho de Filgueiras ${ }^{51}$ também se debruça sobre a passividade com que a população assiste aos escândalos de corrupção no Brasil.

Casos de mal conservação de recursos públicos, uso indevido da máquina administrativa, redes de clientelismos e tantas outras mazelas configuram uma sensação de mal estar coletivo [...] Contudo apesar dessa sucessão de escândalos no Brasil existe uma sensação de impotência por parte da sociedade; a corrupção é tolerada e os cidadãos ficam apenas aguardando qual será o próximo escândalo que circulará nos jornais.

No decorrer de seu estudo Filgueiras ${ }^{52}$ evidencia que muito dessa inércia se constrói na coletividade em relação à descrença nos mecanismos de controle accountability - ou seja, as pessoas não se sentem motivadas a resguardar seus direitos, uma vez que, os órgãos que detém essa incumbência possuem atuação discreta diante da "escancarada" atuação de agentes públicos desonestos. Conforme observado abaixo, apoiados na conceituação criada por O'donnell ${ }^{53}$,

${ }^{51}$ FILGUEIRAS, F. A Tolerância a Corrupção no Brasil: Uma Antinomia Entre Normas Morais e Prática Social. Opinião Pública, Campinas, v. 15, n. 2, p. 386-421, nov. 2009.

52 FILGUEIRAS, F. A Tolerância a Corrupção no Brasil: Uma Antinomia Entre Normas Morais e Prática Social. Opinião Pública, Campinas, v. 15, n. 2, p. 386-421, nov. 2009.

53 O'DONNELL, G. Sobre o Estado, a Democratização e Alguns Problemas Conceituais. Novos Estudos Cebrap, v. 36, p. 123-145, 1993. 
RODRIGUES, Tonny Kerley de Alencar; OLIVEIRA, Daniel Max de; GOMES, Raniele Cimara da Conceição. A relação accountability - corrupção: Uma reflexão conceitual dos achados teóricos. Revista Eletrônica Direito e Política, Programa de Pós-Graduação Stricto Sensu em Ciência Jurídica da UNIVALI, Itajaí, v.11, n.1, $1^{0}$ quadrimestre de 2016. Disponível em: www.univali.br/direitoepolitica - ISSN 1980-7791.

Pinho e Sacramento ${ }^{54}$ reiteram a ineficácia da accountability, destacando que esta encontra-se tanto em seu plano horizontal como no vertical.

No plano vertical, a fraqueza é causada pela existência de sistemas partidários pouco estruturados, alta volatilidade de eleitores e partidos, temas de políticas públicas pouco desenvolvidas e falta de consciência política dos representados. [...] Com referência à dimensão horizontal destaca-se que a efetividade não depende apenas de agências isoladas, mas de uma rede de agências atuando de forma simultânea ${ }^{55}$.

De fato, a proposta da pesquisa de Pinho e Sacramento já pressupõe, como um dos postulados iniciais, a ineficácia da accountability, ou seja, toda a investigação é desenvolvida tendo por base essa constatação, portanto, o que a pesquisa intenta evidenciar é como isso afeta o comportamento da sociedade civil.

\section{CONSIDERAÇÕES FINAIS}

Esta pesquisa teve por objetivo investigar como a relação entre accountability, como um mecanismo de controle, e corrupção é retratada em construtos teóricos referentes a estas temáticas. Procurou-se, ainda, verificar como a accountability tem sido vista sob a ótica de sua eficácia através de trabalhos de natureza científica.

Por meio da análise do corpo teórico existente que trata da relação entre as duas temáticas, percebe-se de forma preponderante que a accountability é retratada como um mecanismo frágil e ineficaz, o que de certa forma difere dos discursos otimistas daqueles que vêem esse recurso como capaz de coibir e até mesmo erradicar problemas como a corrupção dentro do contexto da administração pública brasileira. Constatou-se, por meio dos construtos teóricos, que os casos de corrupção criam na sociedade civil um sentimento de descrença com a coisa

\footnotetext{
54 PINHO, J. A. G.; SACRAMENTO, A. R. S. Accountability: Já Podemos Traduzi-la Para o Português. Revista de Administração Pública, Rio de Janeiro, v. 46, n. 3, p. 1343-1368, nov./dez. 2009.

55 PINHO, J. A. G.; SACRAMENTO, A. R. S. Accountability: Já Podemos Traduzi-la Para o Português. Revista de Administração Pública, Rio de Janeiro, v. 46, n. 3, p. 1343-1368, nov./dez. 2009.
} 
RODRIGUES, Tonny Kerley de Alencar; OLIVEIRA, Daniel Max de; GOMES, Raniele Cimara da Conceição. A relação accountability - corrupção: Uma reflexão conceitual dos achados teóricos. Revista Eletrônica Direito e Política, Programa de Pós-Graduação Stricto Sensu em Ciência Jurídica da UNIVALI, Itajaí, v.11, n.1, $1^{0}$ quadrimestre de 2016. Disponível em: www.univali.br/direitoepolitica - ISSN 1980-7791.

pública o que se converte em uma passividade diante dos episódios de corrupção assistidos.

$\mathrm{Na}$ literatura que intercala accountability e corrupção, raros são os discursos positivos quanto à eficácia dos mecanismos de controle dos atos dos agentes públicos. Percebe-se que quando a accountability é destacada sob uma ótica positiva os autores destacam tal situação com ares de utopia, de uma realidade que seria fundamental para erradicar grandes mazelas que assolam a sociedade, no entanto, algo que ainda está longe da realidade de um país como o Brasil, que encontra-se mais acessível apenas a países altamente desenvolvidos. Dessa forma, a accountability, como um conjunto de mecanismos eficazes, existe, mas bem distante da realidade brasileira.

Destaca-se aqui que, este estudo buscou apenas encontrar lacunas teóricas, em meio a outras pesquisas, que possam ser preenchidas por meio de investigações de maior abrangência e profundidade. Talvez esta seja a limitação mais considerável, não possuir a capacidade de evidenciar aspectos mais significativos sobre o fenômeno estudado, mas claramente a sua elaboração e suas constatações abrem novos horizontes para estudos posteriores que metodologicamente tenham maior impacto para o desenvolvimento das temáticas em questão.

Ainda, argumenta-se que a corrupção representa um fenômeno de dimensões impensáveis e infinitamente exploráveis, ou seja, é um campo fértil para investigações que venham a abordar essa temática. Por meio deste estudo entende-se que procedimentos metodológicos e técnicas das ciências sociais são perfeitamente aplicáveis a estudos do fenômeno da corrupção, no entanto, torna-se necessário a construção de uma teoria social da corrupção que seja capaz de alargar o horizonte de expectativas do conceito. Já para estudos posteriores no âmbito da accountability é sugerido ampliar a ótica de pesquisa utilizada até então, por meio de abordagens quantitativas e qualitativas que coloquem essa temática dentro da agenda de estudos de administração pública do país de forma mais consistente. 
RODRIGUES, Tonny Kerley de Alencar; OLIVEIRA, Daniel Max de; GOMES, Raniele Cimara da Conceição. A relação accountability - corrupção: Uma reflexão conceitual dos achados teóricos. Revista Eletrônica Direito e Política, Programa de Pós-Graduação Stricto Sensu em Ciência Jurídica da UNIVALI, Itajaí, v.11, n.1, $1^{0}$ quadrimestre de 2016. Disponível em: www.univali.br/direitoepolitica - ISSN 1980-7791.

\section{REFERÊNCIAS DAS FONTES CITADAS}

ABRANTES, R. B. Corrupção e Instituições Políticas: Uma Análise Conceitual e Empírica. In: Encontro da Associação Brasileira de Ciências Políticas,7, 2010. Anais ...Universidade Federal de Pernambuco, Recife, 2010.

ABRUCIO, F. L. A Cooperação Federativa no Brasil: A Experiência do Período FHC e os Desafios do Governo Lula. Revista de Sociologia Política, Curitiba, n. 24, p. 41-67, jul. 2005.

- Trajetória Recente da Gestão Pública Brasileira: Um Balanço Crítico e a Renovação da Agenda de Reformas. Revista Brasileira de Administração Pública, Rio de Janeiro, v. 1, p. 77-87, 2007.

ARAÚJO, M..; SANCHEZ, O. A. A Corrupção e os Controles Internos do Estado. Lua Nova: Revista de Cultura e Política, São Paulo, v.65, p. 137-173, mai./ago. 2005.

BELlOTTO, H. L. Arquivos Permanentes: Tratamento Documental. Rio de Janeiro: Editora FGV, 2004.

BEZERRA, M. O. Corrupção: Um Estudo Sobre Poder Público e Relações Pessoais no Brasil. Rio de Janeiro. Relume-Dumará. 1995.

BREI, Z. A. A Corrupção: Causas, Consequências e Soluções Para o Problema. Revista de Administração Pública, v. 30, n. 3, p. 103-115, mai./jun. 1996a.

Corrupção: Dificuldades Para a Definição e Consenso. Revista de Administração Pública, Rio de Janeiro, v. 30, n.1, p. 64-76, jan./fev.1996b.

CAMPOS, A. M. Accountability: Quando Poderemos Traduzi-la Para o Português? Revista de Administração Pública. Rio de Janeiro, v. 4, n. 2, pp. 30-50, fev./abr.1990.

FILGUEIRAS, F. A Tolerância a Corrupção no Brasil: Uma Antinomia Entre Normas Morais e Prática Social. Opinião Pública, Campinas, v. 15, n. 2, p. 386421, nov. 2009.

; ARANHA, A. L. M. Controle da Corrupção e Burocracia da Linha de Frente: Regras, Discricionariedade e Reformas no Brasil. Revista de Ciências Sociais, Rio de Janeiro, v. 54, n. 2, p. 349-387, 2011.

GIL, A.C. Métodos e Técnicas de Pesquisa Social, Atlas: São Paulo, 1999.

GRAY, R. Thirty Years of Social Accounting, Reporting and Auditing: What (if anything) Have We Learnt? Business Ethics, EuropeanReview, v. 10, n.1, p.915, 2001.

LARROUDÉ, E. R. A. Accountability de Organizações do Espaço Público não-Estatal: Uma Apreciação Crítica da Legislação Brasileira. 2006. 
RODRIGUES, Tonny Kerley de Alencar; OLIVEIRA, Daniel Max de; GOMES, Raniele Cimara da Conceição. A relação accountability - corrupção: Uma reflexão conceitual dos achados teóricos. Revista Eletrônica Direito e Política, Programa de Pós-Graduação Stricto Sensu em Ciência Jurídica da UNIVALI, Itajaí, v.11, n.1, $1^{0}$ quadrimestre de 2016. Disponível em: www.univali.br/direitoepolitica - ISSN 1980-7791.

Dissertação(Mestrado) - Fundação Getúlio Vargas, Escola de Administração de Empresas de São Paulo. São Paulo: FGV, 2006.

LOUREIRO, M. R.; TEIXEIRA, M. A. C.; MORAES, T. C. Democratização e Reforma do Estado: O Desenvolvimento Institucional dos Tribunais de Contas no Brasil Recente. Revista de Administração Pública, Rio de Janeiro, v. 43, n.4, pp.739-772, jul./ago. 2009.

MAANEN, J. V. Reclaiming Qualitative Methods for Organizational Research: A Preface, Administrative Science Quaterly, v. 24, n. 4, p. 520-526, dec. 1979.

MELO, C. A. V. Alta Corrupção Como Resposta a Baixos Níveis de Accountability.2003, 185 f. Dissertação (Mestrado em Ciências Políticas) Centro de Filosofia e Ciências Humanas, Universidade Federal de Pernambuco, Recife, 2003.

MELO, M. A. "Governance e Reforma do Estado: O Paradigma Agente X Principal", Revista do Serviço Público, v. 120, n.1, Brasília, jan.-abr., 1996.

MELO, M. P.; SILVA, M. A. Corrupção: "É Proibido Não Proibir". Reflexões Sobre a Moralidade e Improbidade na Administração Pública. Revista Jurídica, v.17, n. 33, p. 195-218, jan./jun. 2013.

MORENO, A. C. Resultados das Manifestações de Junho. Disponível em: <http://g1.globo.com/brasil/linha-tempo-manifestacoes-2013/pla tb/category/sem-categoria/>. Acesso em: 15 mar. 2014.

O'DONNELL, G. Sobre o Estado, a Democratização e Alguns Problemas Conceituais. Novos Estudos Cebrap, v. 36, p. 123-145, 1993.

PEREIRA, J. M. Reforma do Estado e Controle da Corrupção da Corrupção no Brasil. Revista de Administração Mackenzie, São Paulo, v. 4, n. 1, p. 39-58, 2008.

PEREIRA, J. M. Reforma do Estado e Transparência: Estratégias de Controle da Corrupção no Brasil. In: Congresso Internacional Del CLAD Sobre la Reforma Del Estado y de la Administración Pública, 7, 2002. Anais... CLAD, Lisboa, 2002.

PINHO, J. A. G.; SACRAMENTO, A. R. S. Accountability: Já Podemos Traduzi-la Para o Português. Revista de Administração Pública, Rio de Janeiro, v. 46, n. 3, p. 1343-1368, nov./dez. 2009.

. Corrupção e Accountability no Brasil: Um Olhar A partir de Organizações da Sociedade Civil. In: ENCONTRO DA ASSOCIAÇÃO NACIONAL DE PESQUISA E PÓS-GRADUAÇÃO EM ADMINISTRAÇÃO, 36, 2012. Anais... Rio de Janeiro: Anpad, 2012.

POWER, T. J.; GONZÁLEZ, J.Cultura Política, Capital Social e Percepções Sobre Corrupção: Uma Investigação Quantitativa em Nível Mundial, Revista Sociologia Política, Curitiba, v. 21, p. 51-69, nov. 2003. 
RODRIGUES, Tonny Kerley de Alencar; OLIVEIRA, Daniel Max de; GOMES, Raniele Cimara da Conceição. A relação accountability - corrupção: Uma reflexão conceitual dos achados teóricos. Revista Eletrônica Direito e Política, Programa de Pós-Graduação Stricto Sensu em Ciência Jurídica da UNIVALI, Itajaí, v.11, n.1, $1^{0}$ quadrimestre de 2016. Disponível em: www.univali.br/direitoepolitica - ISSN 1980-7791.

SODRÉ, A. C. A.; ALVES, M. F. C. Relação Entre Emendas Parlamentares e Corrupção Municipal no Brasil: Estudos dos Relatórios do Programa de Fiscalização da Controladoria Geral da União. Revista de Administração Contemporânea, Curitiba, v. 14, n. 3, p. 414-433. Mai./jun. 2010.

SPECK, B. W. et al. Os Custos da Corrupção. Cadernos Adenauer, São Paulo, n. 10 , p. $9-127,2000$.

Submetido em: Março/2016

Aprovado em: Abril/2016 